WellBeing International

WBI Studies Repository

2002

\title{
Canis Lupus Cosmopolis: Wolves in a Cosmopolitan Worldview
}

William S. Lynn

Center for Humans and Nature

Follow this and additional works at: https://www.wellbeingintlstudiesrepository.org/acwp_habr

Part of the Animal Studies Commons, Nature and Society Relations Commons, and the Population Biology Commons

\section{Recommended Citation}

Lynn, W. S. (2002). Canis lupus cosmopolis: wolves in a cosmopolitan worldview. Worldviews: Global Religions, Culture, and Ecology, 6(3), 300-327.

This material is brought to you for free and open access by WellBeing International. It has been accepted for inclusion by an authorized administrator of the WBI Studies Repository. For more information, please contact wbisr-info@wellbeingintl.org.






\title{
Canis Lupus Cosmopolis: Wolves in a Cosmopolitan Worldview
}

William S. Lynn

Center for Humans and Nature

\section{KEYWORDS}

cosmopolis, cosmopolitanism, cosmopolitan worldviews, ethics, wolves

\begin{abstract}
The subject of wolf recovery in North America sparks heated controversy, both for and against. This paper explores how this subject is informed by cosmopolitan worldviews. These worldviews pull nature and culture into a common orbit of ethical meaning, with implications for the normative relationships that ought to pertain in landscapes shared by people and wolves. This theoretical outlook is illustrated using the controversy over wolves in the northeastern region of the United States. I conclude with a set of reflections on theorizing the cosmopolis, the interpretation of cosmopolitan landscapes, and living with cosmopolitan wolves.
\end{abstract}

\section{Introduction}

What drives opposition to the recovery of predators like wolves? Perhaps the most visceral reason is fear-fear of personal injury, fear of the unknown, fear for the safety of family and friends. A colleague from Spain related her feelings at watching a pack of wolves pass by their campsite at night during a full moon. Her fear was palpable, and admittedly based on unflattering cultural myths about wild canids. I could sense the chill as she told her story, and a story from William Bartram sprang to mind. An eighteenth century American naturalist, Bartram was exploring the wilds of Florida. One night he awoke to find his fish spirited away by a wolf. He reflects on "the unexpected and unaccountable incident, which however pointed out to me an extraordinary deliverance or protection of my life, from the rapacious wolf that stole my fish from over my head." (Bartram 1973, 156)

How much easier and more eligible might it have been for him to have leaped upon my breast in the dead of sleep, and torn my throat, which would have instantly deprived me of life, and then gutted his stomach for the present with my warm blood, and dragged off my body, which would have made a feast afterwards for him and his howling associates! I say, would not this have been a wiser step, than to have made protracted and circular approaches, and then after, by chance, espying the fish over my head, with the greatest of caution and silence rear up, and take them off the snags one by one, then make off with them, and that so cunningly as not to awaken me until he had fairly accomplished his purpose? (Bartram 1973: 157) 
For my colleague, her dread was counterbalanced by wonder, and we excitedly shared stories of encounters with wild animals. Fear and dread is a normal and often appropriate human reaction, especially towards large carnivorous animals. Having been chased by a grizzly bear, charged by a moose and attacked by dogs, I know this fear. I would never belittle another person for their own. Nonetheless, our fears about wolves are unwarranted from ecological and ethological evidence. We know that wolves are neither beasts of waste and desolation, nor varmints, villains and vermin. They are simply wild beings enmeshed, like ourselves, in the tapestry of life. This common sense insight took the dominant European cultures thousand of years to develop, but it was something the indigenous peoples of North America (and elsewhere) understood long ago. Unfettered by the dualisms of nature/culture or animal/human, their relationship with wolves was characterized by appreciation, not denigration. Many early humans modeled themselves on wolf packs, learning cultural and practical skills from a highly successful species, and wolfderived or wolf-like canids quickly became indispensable (perhaps generative) of human culture. (see Corbett 1995; Cohen 1997; Dunlap 1988; Hall 1978; Lopez 1978; Morell 1997; Tacon and Pardoe 2002) This is not to pretend that direct and violent conflicts between people and wolves never or cannot occur. Although we lack direct prehistoric evidence, it would be unreasonable to suppose that conflicts over food, family or territory never brought wolves and humans to blows. In our day, captive wolves socialized to the presence of humans are more likely to respond to perceived threats and infractions of their social order with often subtle but sometimes overt acts of physical intimidation and aggression (see Klinghammer and Goodmann, 1985). This should be put in context, as attacks by healthy wild wolves are extraordinarily rare and virtually never lethal. (Linnell 2002; McNay 2002) Still, in spite of many years of observing and interacting with wolves, they still conjure moments of dread in me when, in their moods or my ignorance, I do something to which they respond with displeasure. They remind me that while our species is dominant on earth by virtue of cognitive acuity, complex social organization, advanced technology, sheer numbers and a regrettable disposition to species cleansing, homo sapiens are pitiful beings in terms of natural strength, agility and perception. There is both humility and wonder to be gained from this insight. ${ }^{1}$

Fear aside, what else may account for the resistance to wolf recovery? Some say it reflects our ignorance of the role played by wolves in the maintenance of ecological function and biodiversity. Others claim it is economic self-interest, extremist ideologies of individualism, erroneous models of property rights, or antigovernment sentiments. Still others point to Euro-America's cultural prejudices against predators. All these explanations have a share of the truth. (see Busch 1994; Dunlap 1988; Lopez 1978; Maclntyre 1996; Mighetto 1991; Sharpe et al. 2001) There is, however, an additional element that remains underinvestigated-the moral discourse that underpins or undercuts this resistance. We should ask, therefore, what moral arguments and sensibilities might account for the opposition to wolf restoration.

To cut to the chase (a thoroughly wolfish metaphor), I believe that the opposition to wolves is partially rooted in worldviews that model the relationship between nature and culture according to a "natural" moral order or "harmony." This harmony might be thought of as "the best arrangement possible" between the wild and the domesticated. These worldviews are a network of resonant ideas, feelings and experiences, and do not form a coherent system of linear argument and deductive conclusions. Even so, they have strong normative implications that influence the politics of wolves in striking ways.

A moral order uniting nature and humanity bears a striking resemblance to a very old worldview -the cosmopolis. ${ }^{2}$ It is the connections between wolves, ethics and the cosmopolis that I mean to explore in this essay. I begin by discussing the idea of the cosmopolis. Next, I use the debate over wolf recovery in Vermont as a point of departure to explore the cosmopolis of wolf opponents. To facilitate further dialogue, I conclude with a set of reflections on theorizing the cosmopolis, the interpretation of cosmopolitan landscapes, and living with cosmopolitan wolves. To the best of my knowledge, this is the 
first instance that the concept of the cosmopolis has been specified and deployed in this way. Throughout this essay, my intentions are suggestive, not conclusive. As a practical ethicist and hermeneuticist (see Bernstein 1991; Toulmin and Jonsen 1989; Lynn 2003), I resist totalizing discourse. Rather than pretend my argument is definitively final, I hope to earmark a new avenue of interdisciplinary interest for scholars working on animal ethics, animal studies and animal geography-three arenas of interdisciplinary wisdom on which I (gratefully) depend.

\section{The Cosmopolis}

The idea of the cosmopolis emerges in Stoic philosophy during the Greek and Roman Empires of the Mediterranean world. We are not certain of its provenance because the writings of the founders-Zeno of Citium (c. 335-263 BCE) and Chrysippus of Soli (c. 280-207) -are lost to us, as are most of the texts from the early and middle Stoa-the distinct periods of stoic thought (c. 300-250 BCE). Discussions of early doctrines survive primarily in writings from the late Stoa (the first through third century CE). This Stoa was firmly associated with Roman public philosophy, as represented in the writing of Cicero (c. 106-43 BCE), Seneca the Younger (c. 1-65 CE), Epictetus (c. 50-130 CE), and Marcus Aurelius (c. 121-180). (see Becker 1999, chapter 3; Honderich 1995: 852-853)

Mulford Sibley notes that like many religious and philosophical movements of its time, the latter Stoa was a response to the increasing cultural diversity and political integration of the Roman Empire. While this diversity and integration had less effect on the cultural integrity of the countryside, it did transform the urban centres of the Roman Empire. These centres became cities of the (Roman) world, cosmo-poleis or "world-cities," reflecting the wider demographics, economics and politics of Roman life. (Sibley 1977: 115116) The modern notion of a cosmopolitan as a "citizen of the world" is rooted in this line of thinking. Pheng Cheah offers a particularly helpful definition.

Cosmopolitanism is derived from Kosmo-polites, a composite of the Greek words for "world" and "citizen," by way of the esprite cosmopolite of Renaissance humanism. It primarily designates an intellectual ethics, a universal humanism that transcends regional particularism. The regional particularism that is opposed here may be defined territorially, cultural, linguistically, or even racially, but it is not defined nationally as we now understand the term, because in a Europe made up of absolutist dynastic states, the popular national state did not yet exist. Nor indeed, had the doctrine of nationalism been fully articulated. Cosmopolitanism thus precedes the popular nation-state in history and nationalism in the history of ideas. (Cheah and Robbins 1998: 22)

Cheah's foregrounding of the conceptual and temporal distinctions between nationalism and cosmopolitanism signals its use in modern times. Immanuel Kant generated a discussion of cosmopolitanism when he suggested that a cosmopolitan ethic could be instrumental in fostering perpetual peace between European states through a free federation of the same. For Kant, this was instrumental to the ultimate purpose of achieving a unified human race. (Cheah and Robbins 1998: 5976) Contemporary scholars have taken this usage on board, and cosmopolitanism is a core point of debate in global ethics and international affairs. Cheah and Robbins felicitously describe this as a debate over thinking and feeling beyond the boundaries of national and identity politics. In this interpretation, a cosmopolitan person is aware of and engaged with the well-being of the world beyond her locale or nation. This dialogue is especially concerned with the increasing urbanization of societies, the globalization of culture, the multiculturalism of urban life, and the post-national identities of a growing community of "global citizens." Overall, cosmopolitanism is regarded by some as an antidote to parochial national perspectives, and a justification for respecting diversity and pluralism within society. (see Beauregard and Body-Gendrot 1999; Sandercock 1997; Dower 1998; Tomlinson 1999) 
As important as this modern discussion may be, the cosmopolis is an idea far older and more complex than world-citizenship alone implies. So let us return to the Stoic understanding of the cosmopolis, the root-stock that informs—but is not identical to—contemporary debates over cosmopolitanism.

The Stoics are credited with the three-fold division of philosophy into ethics, logic and metaphysics. They made substantial contributions to all these areas. Spanning a wide geography and long history, it should come as no surprise that Stoicism was a diverse philosophy whose doctrines were in dispute. Yet the core of Stoicism was an ethics with the following features.

- Cosmic Telos-According to the Stoics, an all-embracing order founded on reason pervades and unifies all parts of the cosmos. The cosmos is a rational being, and there is a purpose for all things and events. There is thus a macrocosm of purpose in nature at both terrestrial and celestial scales, as well as in the microcosm of humanity's individual and collective lives.

- Naturalistic-The fundamental principle of Stoic ethics was "follow nature." While moderns might baulk at a potential conflation of facts with values, the Stoics saw it differently. Nature (loosely translated here as cosmos) was regarded as the larger order or macrocosm in which the microcosm of humanity was embedded. Since the two were unified, it made sense to look to nature for insight about society. Beyond this, just what "follow nature" means is in some dispute. There were likely several meanings, primarily that we should align our actions with the facts of the world, as well as with the larger purposes of a teleological cosmos.

- Eudaimonia-Stoic ethics was thoroughly eudaimonistic. As opposed to pleasure, power, property and prestige, it identified the good life with the flourishing of people according to the supreme virtue of reason. Originally counseling apatheia, or indifference to worldly matters, later Stoics softened this into a regime of character, building on the use of reason to improve personal and civic life.

- Practical Reason-For Stoics, circumstances always conditioned the findings of moral reasoning. The Stoics looked to context when determining what is good in life, what is ethically justifiable, and what actions are incumbent for the ethical person. This was not a form of situation ethics per se. Rather they were particularistic in the sense of developing broad norms to be situationally applied. (Becker 1998, chapters 1-4; Toulmin and Jonsen 1989, chapters 2-3)

The cosmopolis was both root and fruit of this ethics. Although making a basic distinction between cosmos and polis, that is, between nature and culture, the Stoics believed the universal reason pulled cosmos and polis into a common orbit of ethical meaning. It is this that served as the basis for an ethics that "followed nature." The normative "logic" of Stoic cosmopolitanism ran something like this. Since a moral order pervades nature and culture, our conduct as human individuals and communities is at its best (e.g. "right") when we act naturally, that is, when we act in accord with nature. Seen in this way, a cosmopolis is much more than a world city of transimperial culture and politics. It is a worldview laden with moral values that mutually constitute the realms of nature and culture. (Toulmin 1990: 67-69) Stephen Toulmin (1990: 68) puts it this way.

We find Stoic philosophers fusing the "natural" and "social" orders into a single unit. Everything in the world (they argued) manifests in varied ways an "order" which expresses the Reason that binds all things together. Social and natural regularities alike are aspects of the same overall cosmo + polis-i.e. cosmopolis. The practical idea that human affairs are influenced by, and proceed in step with heavenly affairs, changes into the philosophical idea, that the structure of nature reinforces a rational Social Order. (Toulmin 1990: 68) 
Toulmin develops this idea at length in his celebrated book Cosmopolis: The Hidden Agenda of Modernity (1990). Using the stoic conception as a metaphor for thinking about philosophies of science and society, Toulmin explores how medieval and early modern sensibilities about politics and ethics were informed by contrasting cosmo-political outlooks. These worldviews sought normative resonance between nature and culture, or put another way, a model of nature from which to construct the moral-political artifacts of society. The shift from medieval to early modern theories of science illustrates this nicely.

In the medieval world of Christian Europe, the model for society and nature was the organism. This was not, however, an organicism founded on the beings and processes of nature. Nature was a fallen realm, an unsuitable template for God's moral, social and natural order. It was a spiritual organism, the body of Christ, which was the master metaphor for nature and society, with each plant, animal, person and class having a role to fulfill. Lacking a well-developed knowledge of evolution and ecology, or human and physical geography, scientists of the time (and well before) assumed a special creation for the earth, an anointed role for humankind, and a grand purpose or cosmic teleology to the universe. All this resonated well with ancient doctrines of causation, one of which emphasized cosmic teleology, and a concept of physical and spiritual "substances" that explained the qualities of matter and experience. The Catholic science of this age (then called natural philosophy) was constructed on these pillars. (see Dampier 1984; Lindberg 1992; Livingstone 1992)

By the mid-1500s, however, many were chafing under the Catholic hierarchy's commitment to its science. Growing ranks of European scholars were impressed by the "experimental" methods of physiology and medicine, frustrated by the increasing disjunction between observation, experiment and Aristotelian physics, and shocked by geographical explorations revealing the Bible's omissions of "other worlds" with their distinct cultures, flora and fauna. Natural philosophers were looking for a more adequate worldview, one whose theoretical and empirical rigour could accommodate new data and insights. "Exotic" knowledge had implications for society and political philosophy as well, some of which profoundly challenged orthodox viewpoints on the social and moral order. This included the growth of deistic and heretical religions, the first stirrings of global trade and colonial adventures, the increasing experience of moral and cultural diversity, the first flowering of nationalism, the emergence of absolute monarchy and social contract political philosophies, the rise of commercial and labouring classes, and the corresponding weight of towns or cities in the capitalist regime of accumulation. The Church and princely states sought to preserve their authority, by suppressing dissent theological and political dissent.

Despite the Crusades, excommunications, the Inquisition and missionary movements, the ability of the Roman Church to enforce its views on science and society was finally ended by the Thirty Years Wars (1618-1648). Rooted in the religious struggle between Catholicism and Protestantism, and abetted by dynastic and nationalistic conflict, this war devastated central Europe, bankrupted the participating states of Western Europe, and nourished an imperialistic form of European nationalism. One consequence of this chaos was the discrediting of the medieval Roman Catholic worldview. Prior to the Protestant Reformation and European nationalism, Catholic theology and natural philosophy formed the conceptual framework for understanding the "cosmopolis"-the "truths" of God's creation and his [sic] intentions for human life, including morality, culture, and politics. With the general ferment and unrest in Europe, and in the face of ongoing devastation, the old cosmopolis became untenable. This cleared the way for contending philosophies to re-weave and make whole the European world.

Modern science was one of these contenders. Its vision of an ordered, comprehensible, and mechanically engineered social and natural world held forth a promise of stability for which many Europeans yearned. The atomic and mechanistic metaphors of the day not only lent themselves to experiments of precise calculation and prediction, but were consonant with the increasingly individualist and market-oriented polities emerging in Europe. Thus scientists participated in the ongoing cultural project of reconstituting 
the intellectual edifice of the modern cosmopolis by producing a mechanistic philosophy and quantitative methodology that would purportedly deliver certain, causal, and determinative knowledge for the guidance of human affairs. (Toulmin, chapters 2-4) As God had engineered the Earth and the Universe to perfection before the expulsion from Eden, so too could Humanity engineer itself to (near) perfection as it awaited redemption. While many believed in this literally, including many scientists, over time it really did not matter if theological faith wavered. This cosmopolitan vision of human power and ingenuity harnessing natural forces for the social weal was powerful medicine. And because this project was so successful in empowering humanity over nature, science became a model (some would say the model) for valid knowledge, and the belief in scientism-the claim that science provides the only true or useful knowledge—gained widespread adherence. (see Sorell 1991; White 1968)

The understanding of cosmopolis I use in this essay is akin to Toulmin's. I retain the Stoic emphasis on the normative connections interweaving the human and natural worlds, and the cosmo-political implications this has for how we think about science and society. (for details, see Toulmin 1990, the "Epilogue") While I am sympathetic to the ethical system of the Stoics, I do not adopt it. Rather I am using cosmopolis as a conceptual tool with which to examine the human/wolf relationship afresh. In so doing, I use the word cosmopolis to discuss a worldview where the realms of nature and culture are interlaced by a common moral thread, or put another way, to explore an ethics-laden discourse about humans and nature. The cosmopolis offers a distinct vision of the intertwining moral values that ought to characterize the relationship between the natural and cultural worlds, and in this essay, between wolves and human communities. A cosmopolitan point-of-view reflects the moral vision of a particular cosmopolis, while multiple (and perhaps contesting) visions of the cosmopolis would be cosmopoleis, the plural form of cosmopolis. A cosmopolitan wolf, then, is not a worldly and sophisticated canid! Rather, a cosmopolitan wolf is a wild canid, Canis lupus, viewed through the lens of this kind of nature/culture discourse. In addition, my use of the concept has descriptive, explanatory and normative dimensions. As a description, it helps specify and distinguish plural conceptions of nature and culture. As an explanation, it helps one interpret the intentions, reasons and actions of individuals and society towards wolves, people and the natural world. As a normative vision, it reflects various perspectives on how we ought to live in a morethan-human world. Taken together, a cosmopolitan worldview serves both as a metatheory to guide human understanding of our place in the natural world, and as a signifier of particular instances of such understandings. ${ }^{3}$

\section{The Opposition to Wolves in Vermont}

Grey wolves were endemic to North America, including New England and New York (together, the Northeast), for over 10,000 BP prior to colonization by Europeans. Beginning in the $1600 \mathrm{~s}$, the species was exterminated in the lower 48 states of the US in a little over 400 years. Wolves hung on, despite the intense pressure of hunting and trapping, in the wilds of Canada. The last wolves of the Northeast were officially shot and trapped in the Adirondack Mountains during the 1870s. A hundred years later, modest efforts in the US at wolf recovery (primarily the protection of Minnesota Wolves from extermination) began. By the beginning of the new millennium, wolves were still missing from the vast majority of their previous range, including the Northeast. In the late 1990s, a bitter debate began over restoring wolves to the Northeast. This debate was kindled as agencies of the federal government foresaw restoration possibilities in a network of highlands and watersheds-the Adirondack Mountains of New York, the upper Hudson River Valley, the Green Mountains of Vermont, the White Mountains of New Hampshire, and the Allagash River Basin of Maine. Environmental groups were actively pursuing reintroduction, while property rights, wise use and sportsmen groups were adamantly resisting. (see Brownlow 2000; Elder 2000; Ferris et al. 1999; International Wolf Center 1997; International Wolf Center 2001; Sharpe et al. 2001) 
Most of the attention given these debates has centred on vocal and potentially violent opposition in Adirondack State Park, and antiwolf legislation in New Hampshire and Maine. For my purposes, I want to focus on an alternative instance of this debate-the legislative hearings on a bill to prohibit wolves in the state of Vermont. As a state with a "progressive" environmental record, the debate over wolves seemed less heated than in surrounding states. It then flared up in January of 2000 when the chair of the Vermont House Fisheries and Wildlife Committee, State Representative Richard Helm of Castleton, introduced a measure to prohibit the introduction of wolves into Vermont by federal, state or private agencies. (Helm 2000) The proposed legislation was similar to successful state laws passed in New Hampshire and Maine.

The bill died in committee, but not before Representative Helm held hearings on its merits. ${ }^{4} \mathrm{~A}$ parade of stakeholders lined up to offer advice, including the Vermont Agency of Natural Resources (ANR), hunting and trapping organizations, Defenders of Wildlife (Defenders), the National Wildlife Federation (NWF), and local citizens. ${ }^{5}$ The ANR opposed the bill on the grounds that it was premature, and more information was necessary before any decisions about management should be made. Defenders and the NWF agreed with the ANR, but reminded the committee of the important role played by wolves in healthy ecosystems. As part of their testimony, they proactively addressed arguments against wolf recovery in Vermont, chalking up anti-wolf sentiment to a variety of well-known factors-ecological ignorance, economic self-interest, anti-government sentiments, and cultural myths about predators.

What fascinated me, however, was the discourse of the hunting and trapping clubs. ${ }^{6}$ Their testimony did underscore the critique of environmentalists, being littered with skewed conceptions of wolf ethology and ecology. Even so, I believe I heard something distinct in their talk-a cosmopolitan worldview that ran in parallel with ecologic, economic and political claims. This worldview portrayed humans and wolves as having a "natural" and normative relationship that ought to define their interactions. Two features characterize this relationship. First, wolves and humans should not share space in a common landscape. Where humans tread, wolves should fear to follow. Second, the anthropogenic transformation of natural landscapes is itself a "natural" phenomenon, as are the species extirpations and extinctions it eventuates. In the words of one wolf opponent, "wolves are out of place" in humanized landscapes. In the words of another opponent, wolf recovery is an attempt to "turn back the clock" on the "natural evolution" of Vermont's landscape. Through open discussion in the hearing, the consequence of this line of thinking was clarified. The recovery of wolves in the humanized landscape of Vermont-however rugged and widely forested-is a violation of the "natural order" of things. This violation occurs when wolves are restored to landscapes where proximity and the lack of physical barriers create fluid and overlapping territories that cannot be delineated or policed.

The worldviews expressed by the opponents of wolf recovery were by no means monolithic. For some, it was a matter of leaving wolves where "they are meant to be." Designated wilderness areas in the United States and the "nation of Canada" (a howling wilderness, one presumes) were mentioned as appropriate habitats. Other opponents allowed that if the wolf returned to Vermont "on its own," then that might "prove" that "wolves are meant to be here."7 This later claim about recolonization is especially revealing. It was frequently accompanied by laudatory stories of coyotes. Coyotes were praised for their adaptability in humanized landscapes, and admired for their ability to flourish in spite of lethal animal control and habitat degradation. A business analogy was employed at several points, the coyote being an "entrepreneur," one who takes advantage of new market niches (i.e. habitat). Unable to adapt to new niches, Canis lupus is a business failure, and flunks the acid test of surviving the "natural evolution" of the landscape. The wolf is therefore ecologically unfit, and as a consequence, morally undeserving of a place in the spaces of human activity. ${ }^{8}$ 


\section{Cosmopolitan Reflections}

There is nothing so practical as good theory. Theories help clarify our understandings of the world, and whether right or wrong, serve as touchstones for dialogue. As I said before, I reject totalizing discourses, and I will not try to forestall other insights by insisting on a comprehensive list of my own. Instead I want to posit several theoretical elements that deserve attention, and hope these comments provide something of a road-map for others interested in the exploring the space(s) made(or not) for wolves in a "more than human world." (for a full bodied discussion on this wonderful phrase, see Peterson 2002)

\section{Theorizing the Cosmopolis}

I say "theorizing" as opposed to "the theory of." Why? There are two reasons. First, I want to reemphasize our ignorance of the cosmopoleis that inform our relationship to wolves and nature, and second, I want to underscore a process of dialogue, exploration and pluralism that I would like to see characterize our collective reflections on the cosmopolis.

We have much to learn about the worldviews that influence our relationship to wolves, wildlife and the rest of nature. As can be seen from the Vermont illustration, cosmopolitan worldviews involve a complex play of mutually constituting beliefs and behaviours. Different emphases on landscape evolution, species fitness, spatial separation and entrepreneurial skill were readily apparent in the discourse of wolf opponents at the Vermont legislative hearings. Whether these represent variations on a single cosmopolis, or elements of multiple cosmopoleis is unknown. We are equally ignorant about the cosmopolis of wolf advocates. Defenders of Wildlife is a case in point.

As a leading environmental group advocating wolf recovery in North America, Defenders asserts its identity as a "moderate environmental group," making science-based arguments for protecting endangered species, preserving biodiversity and moving forward with ecological restoration. It explicitly rejects animal-focused moral arguments as they smack of animal rights "extremists." (Fascione 1999; Fascione and Kendrot 2001) Nevertheless, as based on extensive personal conversations, the actual sensibilities of some Defenders employees and members are manifestly ethical. The restoration of wolves has been described to me in various ways-as restitution for past harms to a member of the biotic community, conserving a biological heritage for our children and future generations, the restoration of predatory functions that improve human, animal and ecosystem health, and an opportunity to begin living a more sustainable life. At root, all of these reasons are laden with moral values, as each is in some way concerned with the well-being of human and nonhuman others. In cosmopolitan language, we might say that the moral fabric of the cosmopolis was torn by habitat degradation and species extinction, and the recovery of wolves, whether through reintroduction or recolonization, is a necessary step towards reweaving the moral order of nature and culture.

Pursuing these inquiries will require an interdisciplinary effort of ethicists, scientists and citizens, all of who should inform the politics and practice of wolf recovery. This is especially important with respect to wolves, for our moral and civic dialogue about wolf recovery is too narrowly drawn. There are several reasons for this. In the first place, the research on wolves is dominated by biological and socioeconomic analysis. (e.g. Carbyn et al., 1995) These provide valuable information about wolf ecology, economic costs and benefits, and human social preferences. They do little to describe, adjudicate or prescribe the moral dispositions people harbour (or ought to harbour) towards wolves in the landscape.

In the second place, mainstream environmental philosophy is ill equipped to apprehend the lived moral sensibilities represented by cosmopolitan worldviews. With its emphasis on formal arguments, wolves become vignettes to illustrate the axiological, epistemological and ontological arguments that are often 
the real interest of philosophers. (e.g. Hettinger and Throop, 1999; Lynn 1998b) We must include voices from outside the traditional halls of philosophy to deepen our inquiries, and better apprehend the content, context and consequences of cosmopolitan worldviews. The work on animal ethics, animal geography and animal studies are sources of broader insight in this regard. (e.g. Lutts 1999; Mack 1999; Midgley 1984; Noske 1997; Lynn 1998a; Lynn 2002; Philo and Wilbert 2000; Sax 2000)

The third reason is the skew to public dialogue imparted by the current emphasis on "sound science." In discussions of predator management, sound science looms large, often as an implicit assumption. Sound science is supposed to be the evidence-based, theory-rich baseline for managing wolves. Sound science provides the facts about wolf ecology and ethology, facts that are then added to social preferences (say, a desire for huntable deer) to produce policy. In truth, however, wolves persisted quite well alongside humanity for over a hundred thousand years, all without the "benefit" of wildlife management. It should be clear, then, that humanity's troubled relationship with wolves has little to do with sound science in the sense of empirical data, quantitative models, or management techniques. Instead, our trouble with wolves is a deeply rooted ethical conflict over whether to coexist with wolves and other large predators. Resolving this conflict is a question of values, not facts (even if this puts the matter too strongly), and wolf recovery depends on a culture of tolerance for other life forms and their ways-of-life, not a science of wildlife management. ${ }^{9}$

Another aspect of theorizing the cosmopolis concerns the kind of moral theories deployed. Here I am referring to the unfortunate division between formal and applied ethics. Scholars frequently assume that the moral dimension of public life is adequately mapped by the application of an abstract ethical system. The method here is to overlay one's chosen theory onto the wolf controversy, trusting that one's abstract deductions will produce the proper moral position. For this to work we assume that the abstract ethic is sufficiently broad and perspicuous to cover all contingencies or justifications. Formal ethical systems are tremendously helpful as conceptual tools, and I do not want to gainsay their use. Yet, we should not mistake a priori ethical theories for an inquiry into the ethical self-understandings that inform opposition or support for wolf recovery. Seeking the nascent moral discourses that lie outside the sphere of the academy can be equally helpful. This is especially true when they alert us to new configurations of ideas and practices that are not well represented in the standard conceptual toolbox, yet constitute important points-of-view in public dialogue. To my mind, a better approach is a practical ethics that understands the situated nature of moral understanding, and is sensitized to the reciprocally informing ecology of theoretical insights and empirical cases. Theory should not be divorced from context and practice. Instead it should be well situated in the circumstances of particular cases, and adaptive to changes in context and knowledge over space and time. (see Lynn 2003)

The debate over wolves is a case in point. The opposition to wolf recovery is certainly supported by a moral discourse about humans and wild animals in the landscape. The normative language that characterizes the public debate bears witness to this. Nevertheless, this discourse should not be confused with an established system of animal or environmental ethics (e.g. animal rights, weak anthropocentrism). The discourse of wolf opponents is not a well-honed and abstract conceptual system. It does not depend on sharp axiological arguments about the moral standing of animals, and as a result of this slippage, is not even necessarily anthropocentric. Rather, such axiological arguments are embedded in wider discourses of nature and culture, and make more or less sense to the degree that they resonate with other beliefs about how we ought to dwell on earth. Cosmopolitan worldviews may offer a vision of human moral responsibility to/for nature that is, at least in some respects, altogether distinct from that found in standard conceptual toolbox. A practical ethics should help us unpack this worldview. It would do so not through the development or application of an abstract theory, but by bring a set of moral principles and concepts to bear in a situated manner to help reveal the moral issues at stake, and provide guidance 
on what actions we should take. And it would do this in conjunction with other traditions of scholarship (e.g. anthropology, wildlife management) that contribute their own distinct and valuable insights.

Finally, two broader comments about the use and development of theory itself. First, the most powerful theories are those that help us describe, explain and evaluate the world. Cosmopolitan theorists may want to recover an understanding of ethics as indispensable to explanation in the human and social sciences. Scholars frequently conceptualize ethics as radically different from science. Science, we are told, seeks explanations for natural and social phenomena, while ethics seeks justifications for our actions in the world. Whereas science asks questions such as "what exists" and "what causes that," ethics asks questions like "how shall we live?" and "what ought I do in this situation?" While this distinction is important, it does play into a rigid division of facts from values. In the real world, justifications frequently motivate actions and thus serve as (partial) explanations in human affairs. You cannot understand why some people or communities do as they do, until you understand the full range of their intentions, motivations and presuppositions. The ethical dimensions of these understandings are crucial. Moral norms frequently justify and guide our actions (for good or ill), and are the basis for critiques of oppression and injustice. Ethics is thus a form of discursive power, enabling people to change the world around them via individual and collective action-politics, law, social protest, personal entreaties. In all these senses, then, ethics is an internal concern of the human and social sciences, and essential to the cultural, historical and policy analysis of humans and wolves. As lived ethics, cosmopolitan worldviews may have an under-appreciated impact on the understandings and actions of their adherents. Addressing these worldviews is therefore crucial when we seek to describe, explain or evaluate the human relationship to wolves. (see Bellah 1983; Bernstein 1991; Lynn 2003)

Second, there is a tendency amongst scholars to promote what I term imperialist theory, one designed to colonize and control a field of study, in large part by obliterating the concepts, methods and insights from other traditions of scholarship. This is readily evident in animal and environmental philosophy, where partisans of the value paradigms of anthropocentrism, biocentrism, ecocentrism, animal rights and animal welfare battle for theoretical supremacy. (for examples, see Callicott 1989; Francione 1996; Pepper 1993; Petronivich 1999; Regan 1983) ${ }^{10}$ This is not some ivory tower debate. Animal and environmental activists differentially adopt these theories, and when deployed in political contexts, have counterproductive effects. They may score points in debate with other partisan views, but overall this disposition towards monolithic theory impoverishes our understanding of the world, and obstructs the dialogue necessary to discuss joint issues, common outlooks, points of difference and possibilities for common ground. What we need is a theoretical venture that welcomes a plurality of insights, methods and conceptual innovations. I am arguing here for a modern cosmopolitan sensibility to theorizing the cosmopolis-an awareness and openness to diverse insights and experiences. Theorizing the cosmopolis should be more than describing, explaining or critiquing a moral discourse about nature and culture. It should embody sensibilities that provide an alternative to imperialist theory, and are necessary for a true interdisciplinary endeavour.

\section{Cosmopolitan Landscapes}

Let us return to the concrete, geographic ramifications of cosmopolitan worldviews for the well-being of wolves. Different visions of the nature/culture relationship may naturalize the separation or integration of wolves and humans. For wolf opponents, this moral order may mandate the separation of wolves and humans into distinct natural and cultural landscapes. Blending these landscapes constitutes a violation of moral order, a disharmony. Conversely, the worldview of wolf advocates may also seek to "follow nature," but in this case, following nature means integrating wolves and humans into a common landscape. A landscape without its historic complement of wolves violates the natural order, and awaits the restoration 
of a mixed community of people and animals in nature. (for an extensive discussion of the meaning and implications of mixed communities, see Midgley 1984)

Suppose, for clarification's sake, the discourse of wolf opponents reflects a particular cosmopolis that defines, in broadly moral terms, what wolf-human relations ought to be. This discourse will have significant ramifications for how wolf opponents regard the company of wolves, and any practical ethics of wolf recovery will have to directly engage its presuppositions, intentions and consequences. It may operate in a parallel conceptual universe to ecologic, economic or political arguments, and in the eyes of adherents, trump non-conforming claims about wolves. Cogent pro-wolf arguments may fall on deaf ears, deflected because they are incongruent with this cosmopolitan vision. It may also form a horizon of expectation, setting limits to how much humans ought to tolerate wolves in humanized landscapes. As Toulmin notes,

The beliefs that shape our historical foresight represent our . . . "horizons of expectation." Those horizons mark limits to the field of action in which, at the moment, we see it as possible or feasible to change human affairs, and so to decide which of our most cherished practical goals can be realized in fact. (Toulmin, 1990: 1)

Proposals to restore wolves into humanized landscapes might transgress perceived boundaries of ethically responsible compromise. In addition, a cosmopolitan worldview may shift debate towards a value-laden moral dialogue, even if this works at cross-purposes with policy perspectives that marginalize moral values. (for examples of this marginalization, see Bailey 1984, Decker 1987 and Gilbert and Dodds 1992) As narratives that help create and make sense of particular moral judgments about good or bad wolf management, visions of the cosmopolis form part of the content and context of the wolf debate, and are an indispensable point of dialogue in public policy.

My own view is explicitly value-laden and informed by my training as a geographer. Cosmopolitan worldviews can help us apprehend and critique the moral values informing the anthropogenic evolution of landscape. Humans exercise a profound and troubling "geographic agency" over the globe, which is to say, we have an astonishing ability to modify the earth for good or ill. (see Marsh, 1964; Turner 1990) The geographies we create and destroy reveal the moral landscapes of our lives, as human agency has consequences for human and non-human well-being that are literally drawn on the landscape (e.g. slums, gated communities, clear-cuts, zoos). We interpret these tracings as we describe and explain land use and the condition of the land's inhabitants. Yet description and explanation are not enough. They are incomplete without tracing the normative implications, for all landscapes are laden (for good or ill) with moral values. All landscapes, and especially the landscapes adapted for human use, inevitably privilege some human and wild beings over others. Whether this is good or just in anthropogenic landscapes is a situated judgment that must take account of the intentions, circumstances and consequences of our actions. ${ }^{11}$ As an act of apprehension, we focus on understanding the role and implications of values for describing and explaining how a landscape came to be, whose well-being is served (or not), who is centred, excluded or marginalized, and what counts as a transgression in social and physical space. As an act of critique, we focus on adjudicating those values that privilege some over others, be they humans or wolves, and envision a landscape that promotes rather than detracts from the welfare of the community of life. My overall point is that the cosmopolis can help us interpret why a landscape exists, what kinds of values it embodies, and what we ought to do in its context.

\section{Cosmopolitan Wolves}

As a final reflection, I want to connect wolf recovery with the recovery of a deeper human identity. I have been using the term "recovery" to mean two things. The first meaning is recovery as referring to the 
natural recolonization, or the deliberate human reintroduction, of wolves to former habitats. Wolves are recovering in the American West in both respects, and while one mode or the other seems to matter little to the wolves, it is significant to people holding cosmopolitan perspectives about carnivores. The second meaning is that the recovery of wolves involves more than the presence of a migrating wolf or an occasional den. Recovery should imply a healthy breeding population, one that is capable of persisting over time and space. These are widely shared positions in the literature on wolves, and involve little dispute.

There is, however, a more controversial dimension to recovery that is more problematic, specifically: what constitutes success in wolf recovery? How much (recovery) is enough? There is sharp disagreement here. The US Fish and Wildlife Service (USFWS) define recovery according to a narrow interpretation of the Endangered Species Act. (USFWS 1992; 2000) Environmentalists have taken a more expansive definition to heart. Defenders, for example, has focused on the need for distinct population segments, spatially distributed, so as to promote genetic diversity and avoid catastrophic losses to disease or disaster. (Ferris et al. 1999) Both positions are rooted in biological criteria and legal arguments, and neither addresses our moral responsibilities for wolf recovery and what that might mean.

When I refer to recovery I am not talking about a shallow vision of wolf recovery, one where we simply prevent extinctions (the USFWS position) or distribute wolves as representative samples of biodiversity (Defenders' position). In either sense, wolves become nothing more than another commodity of human society, incarcerated within the walls of zoos, relegated to ghettos called refuge and wilderness, and hounded in the marginal spaces of the humanitat-the spaces of human habitation. Rather, I advocate a deep vision of wolf recovery, one where wolves (and other predators) roam freely alongside human settlement. By recovery then, I mean not only a healthy and breeding population of wolves that arises through recolonization or reintroduction, but a population whose individuals are respected as co-residents in wild and humanized landscapes.

To my mind, a deep recovery of wolves is interlaced with the recovery of our animality, which is to say, our human identity as animals in relationship to other animals. The question of animality looms large in animal studies, and informs how we conceptualize the taxonomy of life (e.g. animals, plants, bacteria, etc.), the social nature of other animals (e.g. cognitive and cultural ethology), and the difference that make us human. (e.g. linguisticality, cultural complexity) (in all these regards, see Creager 2002; Ingold 1988; Mack 1999; Manning and Serpell 1994; Shepard 1996) Our status as animals is not, however, a new question, and mythologies of origin have always sought to place human and other animals into a coherent pattern of creation. This should come as no surprise, as animals are the most culturally and materially significant dimensions of our earthly home. The first prehistoric art was primarily about animals, herding preceded farming, and companion animals remain our closest connection with non-human nature.

I want to be careful, however, not to imply that animals are simply ordinary and familiar, or that our joint humanity/animality is anything but multi-layered, fluid and distinct from other animals. The reality is otherwise, and the alterity of animal, their "otherness," must be acknowledged from the start. As anyone who watches kitty become killer, even those creatures we know so well can surprise us by their otherness. This otherness also structures our experience of animals. We fear some for their power and ferocity (e.g. wolves), gaze at others in awe for their beauty and prowess (e.g. cougars), feel a deep affection for some (e.g. companion dogs), and may feel dispassion for still others (e.g. broiler hens). Our own virtues and vices must make us equally other, if there are sapient non-human animals who bother to think about such things. It is perhaps because of this alterity, that there is no relationship so fraught with the paradoxes of familiarity and strangeness, care and disregard, as that of between people and animals. 
How this alterity informs the understanding of our own humanity is a subject we still struggle to understand. Should we conceive of animal/human alterity in terms of (radical) difference, as is done in human-focused social theory? (see Harvey 1997; Young 1990) Or do animals provide insight into another kind of alterity, one in which continuity is the basis for species identity? Surely it is the later, for the philosophical dualisms that underwrote the strict separation of humans from other animals is crumbling, and the evidence is piling up for a continuum. Scholars involved in animal studies and cognitive ethology make a powerful case for what we might call punctuated continuity—real similarities combined with real differences that are differentially configured along a continuum of features and species. (see Bekoff et al. 2002; Bekoff 2002; Griffin 1992; Wynne 2001)

If then, we can recognize in wolves, as we so easily do in dogs (e.g. Thomas 1992; 2000), a continuity of consciousness and well-being with ourselves, what does that say about the moral boundaries and connections that emerge from our joint animality? Does the moral dimension of our identity as individuals, societies or species map over to wolves, such that however "other" wolves may be (and they are, I assure you), they also have moral standing and significance in our hearts and minds? How ought our moral identities be drawn in a world of wolves and other species so manifestly connected-ethically, ethologically and ecologically—-to our own?

This is not a subject I can settle here. Speaking for myself, my moral identity means that I care not only for members of my own species, but also for a community of life, including wolves. As I welcome the differences and difficulties of human diversity, so too do I welcome the challenges of living with a diversity of animals, including predators like wolves. For me, being fully human means living in the presence of wolves. They may be near or far, but their presence ought to be a precondition of a justifiably human way of life. It is in this sense that I also see Canis lupus as cosmopolitan wolves, wild denizens of the world. By virtue of overlapping identities, people and wolves are drawn into a common orbit of ethical meaning and inhabit a common cosmopolis.

How then do we realize more ethical landscapes? How do we welcome cosmopolitan wolves into the fabric of our lives? We might use multiple criteria to help us take the measure of a landscape's healthe.g. biodiversity, ecosystem health, biophilia, topophilia, multiculturalism, justice, sustainability, etc. Whatever criteria we choose, cosmopolitan worldviews can help us envision and strive towards the wellbeing for the entire community of life-human and non-human, wild and domestic, now and in the future, here and at distant remove. What then would it mean for people and wolves to coexist in shared space, to inhabit a landscape together without the constant threat of human depredation or habitat destruction? The way forward is not entirely clear. At a minimum, it requires that we recognize the moral standing of animals like wolves, and afford them significance in our public policy on the basis of ethical, as well as ecological and social criteria. Too often, it is only social (read economic) and/or ecological criteria that are of significance in public policy. As Holmes Rolston notes, animals like wolves cannot be citizens. Unlike Homo sapiens they are not zoon politikon, the kind of creature capable of participating in political society. Even so, they are certainly residents, co-inhabitants of shared landscapes who "count for the values they carry." (Rolston: 1994, 10) Their well-being in the landscape should count in our moral and political deliberations, which of necessity, includes environmental and wildlife policy, planning and management. Creating landscapes of well-being for wolves is one ethical vision of the landscape, a cosmopolitan vision that helps us critically reflect, collectively deliberate, and take moral responsibility for the practical implications and tangible expressions of human agency on the earth. 


\section{Notes}

${ }^{1}$ I do not want to imply that our species does not have its own physical and cognitive glories. It certainly does, and aside from the more obvious aspects of reason, empathy, linguisticality and dexterity, I want to make explicit my admiration for the beauty and creativity embodied (quite literally) by those engaged in dance, music and art. There is something else too. While we share emotional and psychological dispositions with other animals that are the wellsprings of ethics, we seem to be alone in making ethical norms and practice a fundamental element of our society. We may be, as Mary Midgley has noted, the distinctively "moral primate." (see Midgley 1995; Waal 1997) This ability to care and to act on behalf of others-even at great personal risk-is another virtue of our species.

2 I realize that speaking of "discourse" or "worldview" or "cosmopolis" in the singular can convey an impression of monolithic identity and erasure of difference. This is not my intent, as I fully realize that discourses are plural and contested. My use of singular or plural forms denotes the scale and specificity of my comments. At times I will speak of discourse in general, at others I distinguish between particular discourses. Hence I shuttle between singular and plural forms depending on the context of my remarks.

${ }^{3}$ For a more detailed exposition on this transition, and its importance for the human/social sciences, our understanding of qualitative methodology, and the resonance with a theory of practical ethics, see my dissertation from which this extract was adapted (Lynn 2000).

${ }^{4}$ I testified at these hearings on the indispensable role of ethics and values in policy debates over land use planning and wildlife management, the benefits of an evaluative dimension in stakeholder negotiations, and the necessity of inviting the full range of stakeholders to the table. I stressed that sidestepping an open-ended and deliberative public dialogue over wolf recovery will likely produce "ethics gridlock" over conflicting moral visions and policy options. In the end, gridlock would only undermine the legitimacy of legislative decisions. Much of my time was spent answering questions, debunking claims about intractable conflicts, and advocating for win-win resolutions regarding the funding of feasibility studies and predator compensation funds.

${ }^{5}$ I hasten to add that our concept of a stakeholder should not be restricted to a human person, community or corporation with an economic or social "stake" in the matter. The word stakeholder employs a property metaphor, and usefully conveys the interest human beings have in the outcome of policy decisions regarding land-use and wildlife management. We misuse the word, however, when we restrict the beings who count to legal persons, e.g. adult humans or corporations. This creates a concept frame with illicit presumptions of anthropocentrism and speciesism. We should instead assert a broader meaning to include people as well as animals and landscapes, and endeavour to ensure that the well-being of the entire community of life is duly cared for. Community members may be a more adequate term.

${ }^{6}$ While this is a theoretically directed paper, a brief note on method. As a student of ethics and human geography, I do not depend on statistical methods for empirical research. Rather I engage in various degrees of immersion (e.g. participant observation), open-ended interviews, focus groups, as well as textual and visual interpretation, and interdisciplinary dialogue. These qualitative methods provide the information that conveys the content and meaning of moral discourse. In the case of the Vermont legislative hearings, I took notes with an ear to the concepts, metaphors, illustrations and analogies that advocates and opponents of wolves used in their presentations and discussions. This is informed as well by conversations and public discussions I have had with advocates and opponents alike. I have discussed the ethics of wolf recovery at public conferences and seminars across North America, so I am well placed to listen (and I hope truly hear) divergent views. This description of qualitative inquiry is deceptively simple. For a formalization of this methodology, which I term "discursive case study," see my 
chapters 4-5 in my book manuscript (Lynn 2003, in process). For an extensive overview of qualitative inquiry, see Denzin and Lincoln's Handbook of Qualitative Research (2001).

${ }^{7}$ This was an interesting rhetorical move, because it implies a morally relevant distinction between human restoration and natural recolonization.

8 There is an interesting resonance here between colonialism, ethnic cleansing and the social construction of nature on the one side, and wildlife management, species-cleansing and speciesism on the other. For good points-of-departure into this emerging debate, see the feminist critiques of Salleh (1990), Pluhar (1995), Noske (1997), and Plumwood (1993, 2002). See too where I argue that racism, sexism and speciesism are not (mere) analogies, but variants of anthropocentrism. The main point here is that racism, sexism and ethnocentrism presuppose the "beastialization" of people into non-human (or not quite fully human) others, as the key element in its justification for prejudice and oppression. This insight creates a much stronger resonance between the oppressions people, animals and nature than is heretofore drawn, while expanding the possibilities for solidarity and mutual aid between animal, environmental and social justice movements. (Lynn 1998a; Lynn 1998b; Lynn 2002)

${ }^{9}$ The literature on ecosystems and adaptive management is a good place to begin exploring the benefits and drawbacks of "sound science" as it is applied to wolves in particular, and biodiversity in general (the real focus of concern in this literature). For an introduction, consult Grumbine (1996), Lee (1993) and Noss (1996). Note however, that sound science means different things to different people. For some it has to do with opposing the "junk" science of the anti-environmental movement, for others it is about the rigour of science, and for still others, it is how best to incorporate science into social policy. Without diminishing the importance of these issues, there are two downsides to face. The first is that sound science, as rigour, tends to ignore crucial distinctions between tangible and intangible phenomenon, and associated qualitative and quantitative methodologies. It may consequently diminish the role of ethics and values in social scientific explanation as well as policy development. (see Lynn 2003, chapters 4-6) Sound science in this sense can end up reinforcing an illicit notion of value-free science or value-neutral policy. The second is the use of sound science to forestall actions on behalf of animals and the environment. Conservative, special interest and corporate lobbies use the concept to delay or debunk common sense and precautionary approaches to the environment. A brief search of "sound science" on the web will more than demonstrate this point.

${ }^{10}$ There are significant exceptions to this desultory state of affairs. See for example the work of Holmes Rolston (1994) and William Throop (2000). For one admittedly partial attempt to find the resonances between value paradigms, see Lynn (1998a; 1998b) where I outline the value paradigm of geocentrism.

11 The mere fact that a landscape has been adapted for a human purpose is no guarantee that the purpose was instrumentally desirable or ethically justifiable. Post hoc judgment of land development does little to improve matters. While land use planning is suppose to "rationalize" the development process, its economistic outlook is rarely the most suitable or least destructive paradigm to deploy (see Beatley 1994). And community involvement is only as good as the community that participates. Such communities can be deeply problematic when they are fronts or dupes of corporate interests and local elites intent on manipulating the public process for private ends. 


\section{References}

Bailey, James A. 1984. Principles of Wildlife Management. New York: John Wiley \& Sons.

Bartram, William. 1973. Travels through North and South Carolina, Georgia, East and West Florida. Savannah: Beehive Press. Originally published in 1792.

Beatley, Timothy. 1994. Ethical Land Use: Principles of Policy and Planning. Baltimore: John Hopkins University Press.

Beauregard, Robert A., and Sophie Body-Gendrot, ed. 1999. The Urban Moment: Cosmopolitan Essays on the Late-20th-Century City, Thousand Oaks: Sage.

Becker, Lawrence C. 1998. A New Stoicism. Princeton: Princeton University Press. Bekoff, Mark, Colin Allen, and Gordon Burghardt, eds. 2002. The Cognitive Animal: Empirical and Theoretical Perspectives on Animal Cognition. Cambridge: MIT Press.

Bekoff, Mark. 2002. Minding Animals: Awareness, Emotions, and Heart. New York: Oxford University Press.

Bellah, Robert N., Norma Haan, Paul Rabinow, and William Sullivan. 1983. Social Science as Moral Inquiry. New York: Columbia University Press.

Bernstein, Richard J. 1991. Beyond Objectivism and Relativism: Science, Hermeneutics and Praxis. Philadelphia: University of Pennsylvania Press.

Brownlow, Alec. 2000. "A Wolf in the Garden: Ideology and Change in the Adirondack Landscape." In Animal Spaces, Beastly Places: New Geographies of Human-Animal Relations, edited by C. Philo and C. Wilbert. London: Routledge.

Busch, Robert. 1994. Wolf Songs: The Classic Collection of Writing About Wolves. San Francisco: Sierra Club Books.

Callicott, J. Baird. 1989. In Defense of the Land Ethic: Essays in Environmental Philosophy. Albany: State University of New York Press.

Carbyn, L and S. Fritts, and D. Seip, eds. 1995. Ecology and Conservation of Wolves in a Changing World. Edmonton: Canadian Circumpolar Institute.

Cheah, Pheng, and Bruce Robbins, eds. 1998. Cosmopolitics: Thinking and Feeling Beyond the Nation. Minneapolis: University of Minnesota Press.

Cohn, Jeffrey. 1997. "How Wild Wolves Became Domestic Dogs." BioScience 47 (11):725-728.

Corbett, Laurie. 1995. "Dingoes: Expatriate Wolves or Native Dogs?" Nature Australia 2 (Summer).

Crosby, Alfred W. 1986. Ecological Imperialism: The Biological Expansion of Europe, 900-1900. New York: Cambridge University Press.

Dampier, William Cecil. 1984. A History of Science, and Its Relations with Philosophy and Religion. Cambridge: Cambridge University Press.

Decker, Daniel J., and Gary R. Goff, eds. 1987. Valuing Wildlife: Economic and Social Perspectives. Boulder: Westview Press.

Denzin, Norman K., and Yvonna S. Lincoln, ed. 2000. Handbook of Qualitative Research, Second edition. Thousand Oaks, California: Sage.

Donnelley, Strachan. 1998. "Civic Responsibility and the Future of the Chicago Region," Nature, Polis, Ethics: Chicago Regional Planning, A Special Supplement of the Hastings Center Report, 2-5.

Dower, Nigel. 1998. "World Ethics." In Encyclopedia of Applied Ethics, edited by Ruth Chadwick et al. New York: Academic Press.

Dunlap, Thomas. 1988. Saving America's Wildlife: Ecology and the American Mind, 1850-1990. Princeton: Princeton University Press.

Elder, John, ed. 2000. The Return of the Wolf: Reflections on the Future of Wolves in the Northeast. Hanover: University Press of New England.

Fascione, Nina. 1999. "Remarks on Ethics, Wolf Restoration, and Stakeholder Negotiations." Paper for Exploring Ethics and Values in Fisheries and Wildlife, a conference sponsored by the 
Organization of Wildlife Planners, National Conservation Training Center of the US Fish and Wildlife Service, Shepherdstown, West Virginia, 16-20 May 1999.

Fascione, Nina, and Stephen R. Kendrot. 2001. "Facilitating Citizen Participation in Adirondack Wolf Recovery." In Wolves and Human Communities: Biology, Politics, and Ethics, edited by V. A. Sharpe, S. Donnelley and B. Norton. Washington, DC: Island Press.

Ferris, Robert, Mark Shaffer, Nina Fascione, Heather Pellet, and Michael Senatore. 1999. Places for Wolves: A Blueprint for Restoration and Long-Term Recovery in the Lower 48 States, Washington, DC: Defenders of Wildlife.

Francione, Gary L. 1996. Rain Without Thunder: The Ideology of the Animal Rights Movement. Philadelphia: Temple University Press.

Gilbert, Frederick F., and Donald G. Dodds. 1992. The Philosophy and Practice of Wildlife Management. Second Edition. Malabar, FL: Krieger Publishing.

Griffin, Donald R. 1992. Animal Minds. Chicago: University of Chicago Press.

Grumbine, R. Edward. 1996. "Reflections on 'What is Ecosystem Management."' Conservation Biology 11 (1):41-47.

Hall, Roberta L., and Henry S. Sharp, ed. 1978. Wolf and Man: Evolution in Parallel. New York: Academic Press.

Harvey, David. 1997. Justice, Nature and the Geography of Difference. Cambridge: Blackwell.

Helm, Richard. 2000. H690-An Act Relating to a Prohibition Against Introduction of Wolves into Vermont, Montpelier, VT: Vermont House of Representatives.

Hettinger, Ned and Bill Throop. 1999. "Refocusing Ecocentrism: De-emphasizing Stability and Defending Wildness." Environmental Ethics, 21, 3-21.

Honderich, Ted, ed. 1995. The Oxford Companion to Philosophy. Oxford: Oxford University Press.

International Wolf Center. 1997. Wolves Around the World, 1997 Update. Ely, Minnesota: International Wolf Center.

—. 2001. The Global Challenge of Living with Wolves. Ely, Minnesota: International Wolf Center.

Klinghammer, Erich, and Patricia A. Goodmann. 1985. The Management and Socialization of Captive Wolves (Canis lupus) at Wolf Park Ethology Series, No. 2. Battle Ground, IN: North American Wildlife Park Foundation, Inc.

Lee, Kai N. 1993. Compass and Gyroscope: Integrating Science and Politics for the Environment. Covela: Island Press.

Lindberg, David C. 1992. The Beginnings of Western Science: The European Scientific Tradition in Philosophical, Religious, and Institutional Context, 600 BC to AD 1450. Chicago: University of Chicago Press.

Linnell, John D. C. et al. 2002. The Fear of Wolves: A Review of Wolf Attacks on Humans. Trondheim: NINA-Norsk Institutt for Naturforskning, A Large Carnivore Initiative for Europe.

Livingstone, David N. 1992. The Geographical Tradition: Episodes in the History of a Contested Discipline. Oxford: Basil Blackwell.

Lynn, William S. 1998a. "Animals, Ethics and Geography." In Wolch, Jennifer and Jody Emel eds. Animal Geographies: Place, Politics and Identity in the Nature-Culture Borderlands., London: Verso, 280298.

—. 1998b. "Contested Moralities: Animals and Moral Value in the Dear/Symanski Debate." Ethics, Place and Environment 1, 223-242.

—. 2000. "Geoethics: Ethics, Geography and Moral Understanding." Doctoral Dissertation, Department of Geography, University of Minnesota, Minneapolis.

—. 2002. "Wolves Along the Hudson: The Ethics of Wolf Recovery in the Humanized Landscapes." Paper for the Wolves Along the Hudson seminar, Vassar College, Poughkeepsie, NY, USA, 22 September. 
—. 2002. "Animals: A More-Than-Human World." In Patterned Ground: Ecologies and Geographies of Nature and Culture, edited by S. Harrison, S. Pile and N. Thrift. London: Reaktion Press, forthcoming.

—. 2003. Situated Ethics. "In progress." Draft chapters can be found at www.practicalethics.net.

Lopez, Barry Holstun. 1978. Of Wolves and Men. New York: Scribners.

Lutts, Ralph H. 1999. The Wild Animal Story. Philadelphia: Temple University Press.

Marsh, George Perkins. 1965. Man and Nature, or, Physical Geography as Modified by Human Action. Cambridge: Belknap Press. Originally published in 1864.

McIntyre, Rick, ed. 1996. War Against the Wolf: America's Campaign to Exterminate the Wolf. Stillwater: Voyageur Press.

Mack, Arien. 1999. Humans and Other Animals. Columbus: Ohio State University Press.

McNay, Mark E. 2002. A Case History of Wolf-Human Encounters in Alaska and Canada. Juneau: Alaska Department of Fish and Game.

Midgley, Mary. 1984. Animals and Why They Matter. Athens: University of Georgia Press.

—. 1995. The Moral Primate: Humans, Freedom and Morality. New York: Routledge.

Mighetto, Lisa. 1991. Wild Animals and American Environmental Ethics. Tucson: University of Arizona Press.

Morell, Virginia. 1997. "The Origin of Dogs: Running with the Wolves." Science 276 (13 June): 1647-1648.

Naess, Arne. 1974. "Self-Realization in Mixed Communities of Humans, Bears, Sheep, and Wolves." Inquiry, 22, 231-241.

Noske, Barbara. 1997. Beyond Boundaries: Humans and Animals. Montreal: Black Rose Press.

Noss, Reed, and et al. 1996. Special Section: Conservation Biology, Values, and Advocacy. Conservation Biology 10 (3):904-920.

Pepper, David. 1993. Eco-Socialism: From Deep Ecology to Social Justice. London: Routledge.

Peterson, Anna L. 2001. Being Human: Ethics, Environment and Our Place in the World, Berkeley: University of California Press.

Petrinovich, Lewis. 1999. Darwinian Dominion: Animal Welfare and Human Interests. Cambridge: MIT Press.

Philo, Chris, and Chris Wilbert, eds. 2000. Animal Spaces, Beastly Places: New Geographies of HumanAnimal Relations. London: Routledge.

Plumwood, Val. 1993. Feminism and the Mastery of Nature. New York: Routledge.

- 2002. Environmental Culture: The Ecological Crisis of Reason. New York: Routledge.

Regan, Tom. 1983. The Case for Animal Rights. Berkeley: University of California Press.

Rolston, Holmes, III. 1994. Conserving Natural Value. New York: Columbia University Press.

Sandercock, Leonie. 1997. Towards Cosmopolis: Planning for Multicultural Cities. Boulder: John Wiley \& Sons.

Salleh, Ariel. 1990. Living with Nature: Reciprocity or Control? In Ethics of Environment and Development: Global Challenge, International Response, edited by J. R. Engel and J. G. Engel. Tucson: University of Arizona Press.

Sax, Boria. 2000. Animals in the Third Reich: Pets, Scapegoats, and the Holocaust. New York: Continuum.

Sharpe, Virginia A., Strachan Donnelley, and Bryan Norton, eds. 2001. Wolves and Human Communities: Biology, Politics, and Ethics. Washington, DC: Island Press.

Sheppard, Eric, and William S. Lynn. 2002. "Cities: Imagining Cosmopolis." In Patterned Ground: Ecologies and Geographies of Nature and Culture, edited by S. Harrison, S. Pile and N. Thrift. London: Reaktion Press, forthcoming.

Sibley, Mulford Q. 1970. Political Ideas and Ideologies: A History of Political Thought. New York: Harper \& Row.

—. 1977. Nature and Civilization: Some Implications for Politics. Itasca: F. E. Peacock. 
Sorell, Tom. 1991. Scientism: Philosophy and the Infatuation with Science. London: Routledge.

Tacon, Paul S. C., and Colin Pardoe. 2002. Dogs Make Us Human. Nature Australia Autumn: 53-61.

Thomas, Elizabeth Marshall. 1993. The Hidden Life of Dogs. New York: Houghton Mifflin.

—. 2000. The Social Lives of Dogs. New York: Houghton Mifflin.

Throop, William, ed. 2000. Environmental Restoration: Ethics, Theory and Practice. New York: Humanity Books.

Tomlinson, John. 1999. Globalization and Culture. Chicago: University of Chicago Press.

Toulmin, Stephen and Albert R. Jonsen. 1988. The Abuse of Casuistry: A History of Moral Reasoning. Berkeley: University of California Press.

Toulmin, Stephen. 1990. Cosmopolis: The Hidden Agenda of Modernity. New York: Free Press.

US Fish and Wildlife Service. 1992. Recovery Plan for the Eastern Timber Wolf. Revised 1992 ed. Washington, DC: US Fish and Wildlife Service.

—. 2000. Proposal to Reclassify/Delist the Grey Wolf. In Federal Register, 13 July 2000. Washington, DC: US Fish and Wildlife Service.

Waal, Frans de. 1997. Good Natured: The Origins of Right and Wrong. Cambridge: Harvard University Press.

White, Lynn. 1968. The Historical Roots of Our Ecologic Crisis. In Machina Ex Deo: Essays in the Dynamism of Western Culture, edited by L. White. Boston: MIT Press.

Wynne, Clive. 2001. Animal Cognition: The Mental Lives of Animals. New York: Palgrave.

Young, Iris Marion. 1990. Justice and the Politics of Difference. Princeton: Princeton University Press. 